Research Paper

\title{
Genome-wide RNA-sequencing dataset reveals the prognostic value and potential molecular mechanisms of IncRNA in non-homologous end joining pathway 1 in early stage Pancreatic Ductal Adenocarcinoma
}

\author{
Li-Ming Shang, Xi-Wen Liao, Guang-Zhi Zhu, Ke-Tuan Huang, Chuang-Ye Han, Cheng-Kun Yang, \\ Xiang-Kun Wang, Xin Zhou, Hao Su, Xin-Ping Ye, Tao Peng ${ }^{\bowtie}$
}

Department of Hepatobiliary Surgery, The First Affiliated Hospital of Guangxi Medical University, Nanning, 530021, Guangxi Zhuang Autonomous Region, People's Republic of China.

$\triangle$ Corresponding author: Prof. Tao Peng, Department of Hepatobiliary Surgery, The First Affiliated Hospital of Guangxi Medical University, Shuang Yong Road 6, Nanning, 530021, Guangxi Zhuang Autonomous Region, People's Republic of China. E-mails: pengtao@gxmu.edu.cn, pengtaogmu@163.com. Tel.: (+86)-771-5356528. Fax: (+86)-771-5350031. ORCID ID: http://orcid.org/0000-0001-6133-7078.

(C) The author(s). This is an open access article distributed under the terms of the Creative Commons Attribution License (https://creativecommons.org/licenses/by/4.0/). See http://ivyspring.com/terms for full terms and conditions.

Received: 2019.09.02; Accepted: 2020.02.07; Published: 2020.07.20

\begin{abstract}
Objective: Our current study is to explore the prognostic value and molecular mechanisms underlying the role of IncRNA in non-homologous end joining pathway 1 (LINPI) in early stage pancreatic ductal adenocarcinoma (PDAC).

Methods: Genome-wide RNA-seq datasets of 112 early stage PDAC patients were got from The Cancer Genome Atlas and analyzed using multiple online tools.

Results: Overall survival in high LINPI expression patients was shorter than those with low expression (high-LINPI vs. low-LINPI=481 vs. 592 days, log-rank $\mathrm{P}=0.0432$ ). The multivariate Cox proportional hazard regression model suggested that high-LINPI patients had a markedly higher risk of death than low-LINPI patients (adjusted $\mathrm{P}=0.004$, hazard ratio=2.214, 95\% confidence interval=1.283-3.820). Analysis of genome-wide co-expressed genes, screening of differentially expressed genes, and gene set enrichment analysis indicated that LINPI may be involved in the regulation of cell proliferation-, cell adhesion- and cell cycle-related biological processes in PDAC. Six small-molecule compounds including STOCK1N-35874, fenofibrate, exisulind, NU-1025, vinburnine, and doxylamine were identified as potential LINPI-targeted drugs for the treatment of PDAC.

Conclusions: Our study indicated that LINPI may serve as a prognostic biomarker of early stage PDAC. Analysis of genome-wide datasets led to the elucidation of the underlying mechanisms and identified six potential targeted drugs for the treatment of early PDAC.
\end{abstract}

Key words: IncRNA in non-homologous end joining pathway 1; pancreatic ductal adenocarcinoma; molecular mechanism; prognosis; The Cancer Genome Atlas

\section{Introduction}

The most common primary pancreatic cancer is a tumor that occurs in the exocrine part of the pancreas. It has a high degree of malignancy and a short disease course characterized by rapid development and deterioration. Treating this cancer is difficult because it is often only detected at a late stage, and the mortality rate is high [1]. There are various treatment modalities for pancreatic cancer, including surgery, chemotherapy, radiotherapy and interventional therapy. However, the efficacy of single-modality treatment is limited because pancreatic cancer has a high degree of malignancy [1, 2]. Most patients with pancreatic cancer are difficult to diagnose early; therefore, the resection rate is low, and the five years 
survival rate of patients undergoing tumor resection is $<25 \%$ [3]. Most of pancreatic cancer is pancreatic ductal adenocarcinoma (PDAC). Tumor occurrence is the result of multiple genetic and epigenetic abnormalities. Rapid advances in high-throughput sequencing technology led to the identification of long non-coding RNAs (lncRNAs) as key players in the occurrence, development, and prognosis of cancers [4]. The large amount of high-throughput sequencing data obtained by The Cancer Genome Atlas (TCGA) is helpful for the screening and identification of cancer related biomarkers and therapeutic targets $[5,6]$. Previous studies suggest that lncRNA in nonhomologous end joining pathway 1 (LINP1) plays an oncogenic role in tumors and is significantly correlated with tumor progression and prognosis [7-9]. However, the value of LINP1 for clinical application in pancreatic cancer and its underlying mechanisms remain unclear. Our current study is to explore the prognostic value and potential molecular mechanisms of LINP1 in early stage PDAC.

\section{Materials and methods}

\section{Data acquisition}

The pancreatic cancer RNA-sequencing (RNAseq) dataset included in the present study was got from TCGA data portal (https://portal.gdc.cancer. gov) [5], and the relevant clinical parameters were obtained from the University of California, Santa Cruz Xena (UCSC Xena:http://xena.ucsc.edu/) browser. Criteria for patient inclusion and exclusion were as described in our previous studies [10-12]. The present study included 112 PDAC patients with an early stage [10-12]. The acquisition and use of data in our study were in conformity to TCGA guidelines. Data were derived from TCGA, therefore additional ethics committee approval were not applicable.

\section{Survival analysis of LINP 1 in early stage PDAC}

Survival analysis of LINP1 in early stage PDAC patients was used the multivariate Cox proportional hazard regression model and Kaplan-Meier curve. A time-dependent receiver operating characteristic (ROC) curve was used to assess the power of LINP1 in predicting the prognosis of early stage PDAC patients through the survivalROC package. A nomogram was constructed to assess the contribution of LINP1 to PDAC prognosis prediction. The prognostic value of LINP1 in combination with clinical parameters in PDAC was evaluated using joint effects survival analysis.

\section{Functional assessment of LINPI in early stage PDAC}

The molecular mechanisms underlying the role of LINP1 in PDAC were investigated by identifying differentially expressed genes (DEGs) between lowand high-LINP1 expression groups. LINP1 co-expressed genes in PDAC were identified for functional enrichment analysis, which was input into the Database for Annotation, Visualization and Integrated Discovery (DAVID, https://david.ncifcrf. gov/home.jsp) v6.8 [13,14] and Biological Networks Gene Ontology tool (BiNGO) [15]. The interactions between these genes were examined using GeneMANIA (http://genemania.org/)[16, 17] and the Search Tool for the Retrieval of Interacting Genes/Proteins (STRING, https://string-db.org/) [18-20]. DEGs between different LINP1 expression groups were screened using the edgeR package [21]. Genes meeting the criteria of $\mid \log 2$ fold change $(\log 2 \mathrm{FC}) \mid>1, P$ value less than 0.05 and FDR less than 0.05 were considered as DEGs. LINP1 co-expressing genes were identified by Pearson's correlation coefficient $(\mathrm{P}<0.05)$.

DEGs between different LINP1 expression groups were applied to the Connectivity Map (CMap, https://portals.broadinstitute.org/cmap/) online tool to predict and screen potential LINP1 targeted drugs in PDAC $[22,23]$. The structures of the compounds are available from the PubChem (https://pubchem.ncbi.nlm.nih.gov/) [24]. The molecular mechanisms involved in PDAC different LINP1expression groups were examined by the gene set enrichment analysis (GSEA) approach [25]. The reference gene set used by GSEA was got from the Molecular Signatures Database v6.2 (c2.all.v6.2. symbols.gmt, and c5.all.v6.2.symbols.gmt) [26, 27]. Gene sets with nominal P-value less than 0.05, | Normalized Enrichment Score (NES) | greater than 1 and false discovery rate (FDR) less than 0.25 in the GSEA report were considered reach statistical significance.

\section{Statistical analysis}

Kaplan-Meier curve was assessed by the logrank test. Hazard ratio (HR) and 95\% confidence interval (CI) was used to assess univariate and multivariate Cox proportional hazards regression model. $\mathrm{P}$ value $<0.05$ was considered reach statistical significance. All data statistics were assessed by SPSS version 22.0 and $R$ 3.5.0.

\section{Results}

\section{Survival analysis of LINP 1 in early stage PDAC}

The clinical characteristics of 112 early stage PDAC patients are summarized in Table S1. Survival analysis suggested that high LINP1 expression patients had a poor prognosis compared with these with low expression (high-LINP1 vs. low-LINP1 $=481$ 
vs. 592 days, $\log$-rank $P=0.0432$, Figure 1A-B). The multivariate Cox proportional hazard regression model suggested that high LINP1 expression patients had a notably increased risk of death compared with low LINP1 expression patients (adjusted $P=0.004$; $\mathrm{HR}=2.214 ; 95 \% \mathrm{CI}=1.283-3.820)$. Time-dependent ROC analysis indicated that LINP1 expression was a good predictor of 1 year survival in early stage PDAC with an area under the curve (AUC) of 0.681 (Figure 1C). A nomogram constructed using clinical parameters and LINP1 expression levels indicated that LINP1 contributed more than 30 points to the prognosis, which was higher than the score for clinical parameters such as radiation therapy and alcohol consumption history (Figure 2). Joint effects survival analysis of the value of LINP1 combined with clinical parameters for predicting the overall survival (OS) of patients with PDAC showed that LINP1 significantly improved the ability to predict prognosis (Figure 3A-D, Table S2).

\section{Genome-wide co-expression analysis of LINPI in PDAC}

The results of genome-wide co-expression analysis of LINP1 in PDAC tumor tissues are summarized in Table S3. A total of 774 genes were recognized as co-expressing protein coding genes of LINP1 in PDAC tumor tissues, of which 99 were negatively correlated and 675 were positively correlated (Figure 4). Gene Ontology (GO) term analysis revealed that LINP1 co-expressed genes may be play a role in biological processes, such as $\mathrm{T}$ cell receptor signaling pathway, G2/M transition of the mitotic cell cycle, cell-cell adherens junctions, cell division, cell-cell adhesion, the epidermal growth factor receptor (EGFR) signaling pathway, cell proliferation and the G2 DNA damage checkpoint (Table S4). The BINGO results also confirmed the above results, and indicated that LINP1 co-expressed genes may be play a role in the cell cycle, cell division, cell adhesion mediated by integrin, regulation of cell migration, MAPKKK cascade, and the EGFR signaling pathway (Figure S1). Kyoto Encyclopedia of Genes and Genomes (KEGG) analysis revealed that LINP1 co-expressed genes are play a role in the AMPK signaling pathway, adherens junction, proteoglycans in cancer, cell cycle, metabolism of xenobiotics by cytochrome P450, and the Hedgehog signaling pathway (Table S5). Construction of gene-gene interaction (GGI) (Figure 5) and protein-protein interaction (PPI) (Figure 6) regulatory networks using GeneMANIA and STRING online tools led to the identification of a complex network of regulatory relationships among LINP1 co-expressed genes.
A

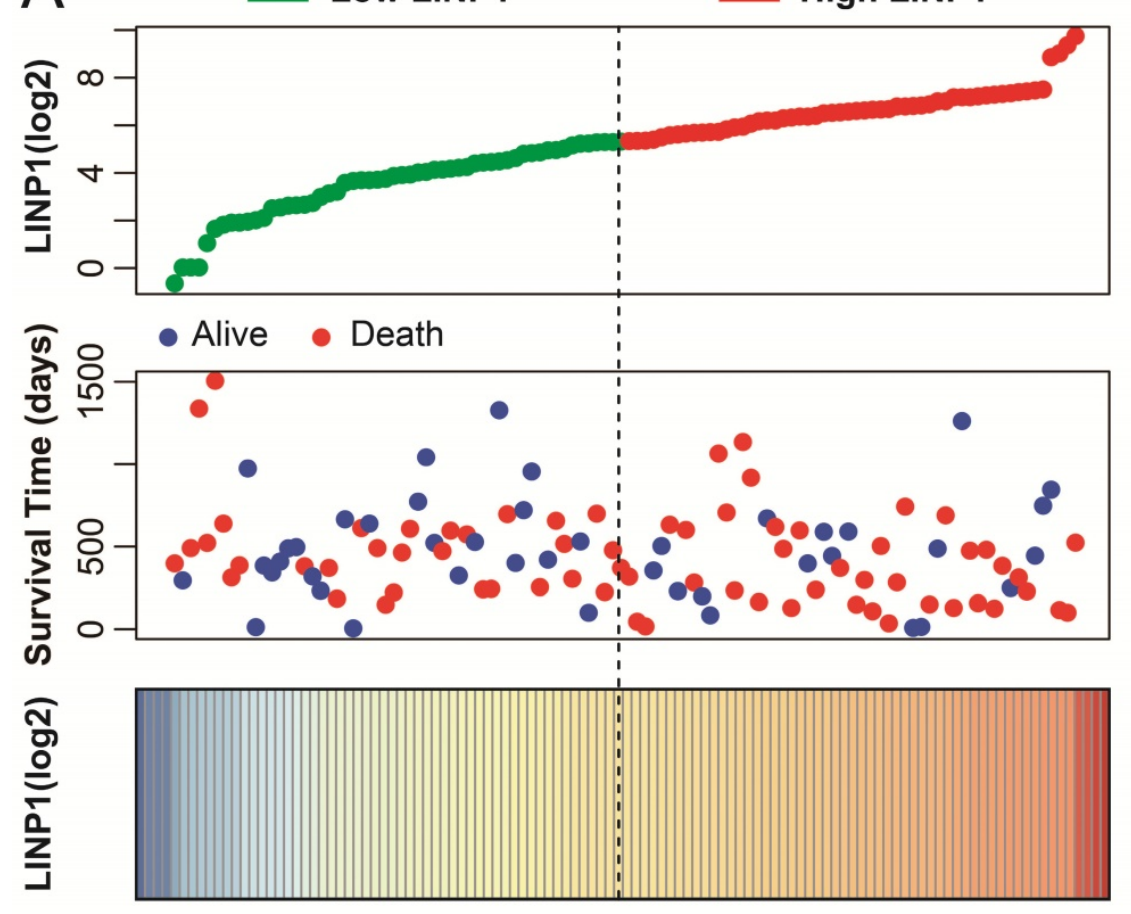

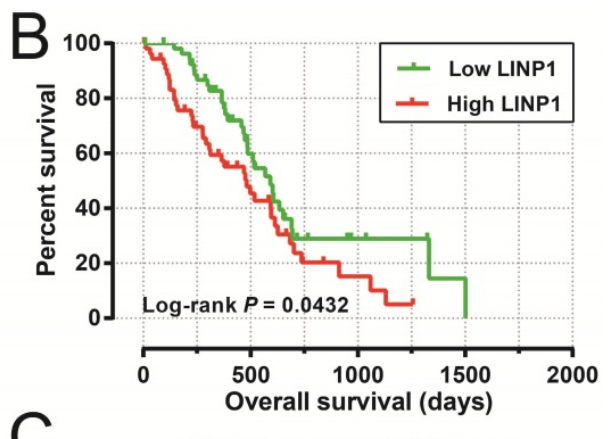

C

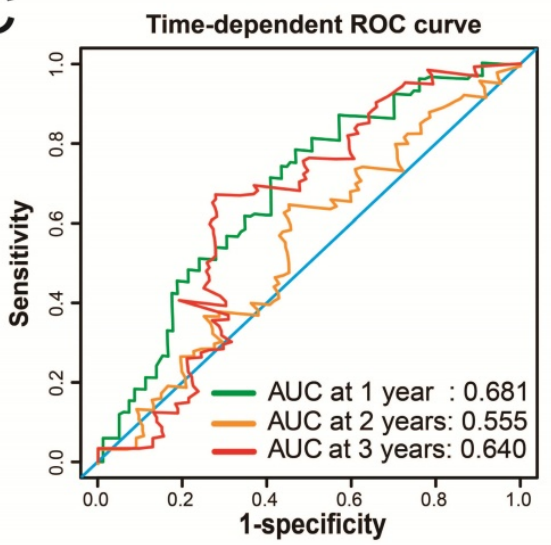

Figure 1. Survival analysis of LINP1 expression levels in early stage pancreatic adenocarcinoma (PDAC). (A) Relationship between LINP1 expression and OS in patients with PDAC. (B) Kaplan-Meier curve of the effect of LINPI expression on OS in patients with PDAC. (C)Time dependent ROC curve of LINPI for PDAC clinical outcome prediction. 
Points

$\begin{array}{lllllllllll}0 & 10 & 20 & 30 & 40 & 50 & 60 & 70 & 80 & 90 & 100\end{array}$

Age (years)

Alcohol history

Gender

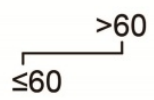

Histological grade

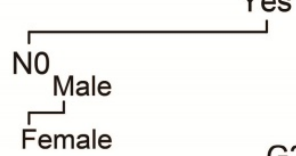

Pathological stage

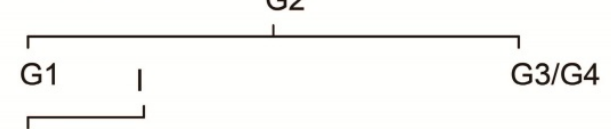

Radiation therapy

Radical resection

II NO

Targeted molecular therapy

LINP1

Total Points

1-year survival

2-year survival

3-year survival

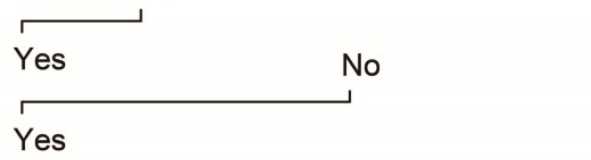

Yes

High expression

Low expression

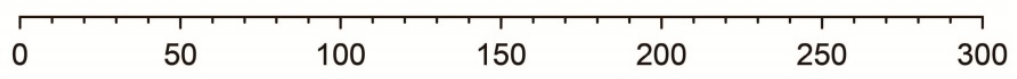

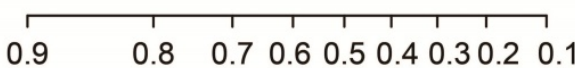

$\begin{array}{llllllllllll}0.7 & 0.6 & 0.5 & 0.4 & 0.3 & 0.2 & 0.1\end{array}$

$\begin{array}{llllll}0.6 & 0.5 & 0.4 & 0.3 & 0.2 & 0.1\end{array}$

Figure 2. Nomogram of the combination of LINPI with clinical parameters for predicting the prognosis of patients with early PDAC.

A

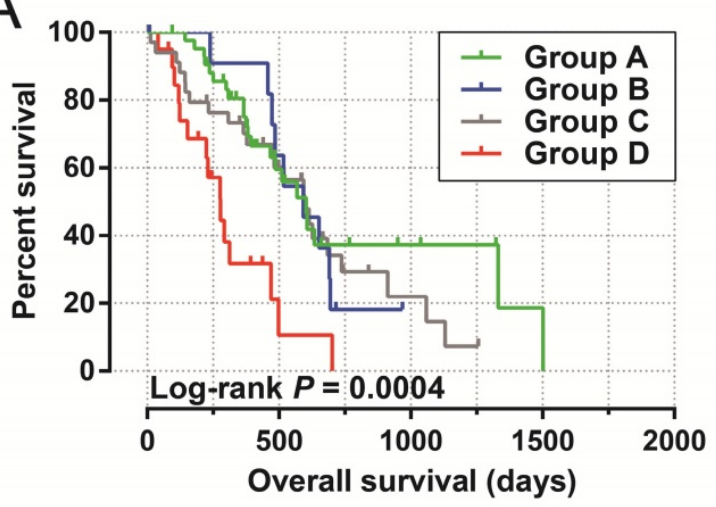

C

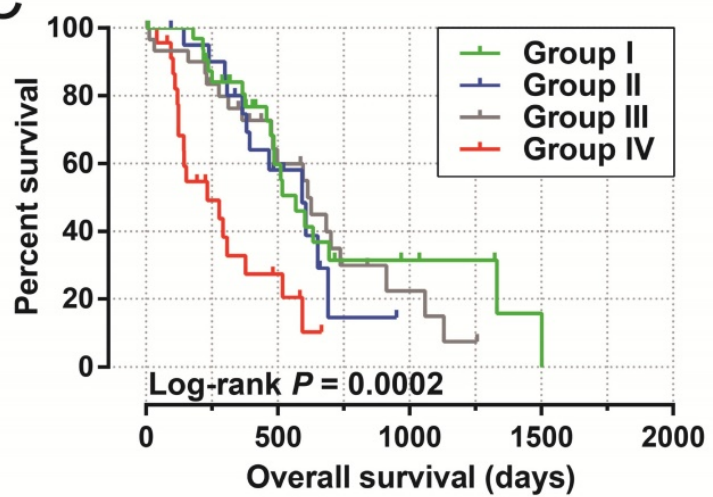

B

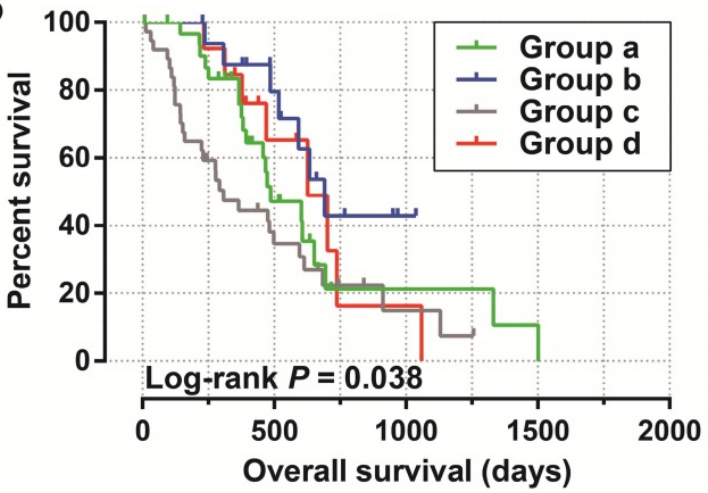

$\mathrm{D}$

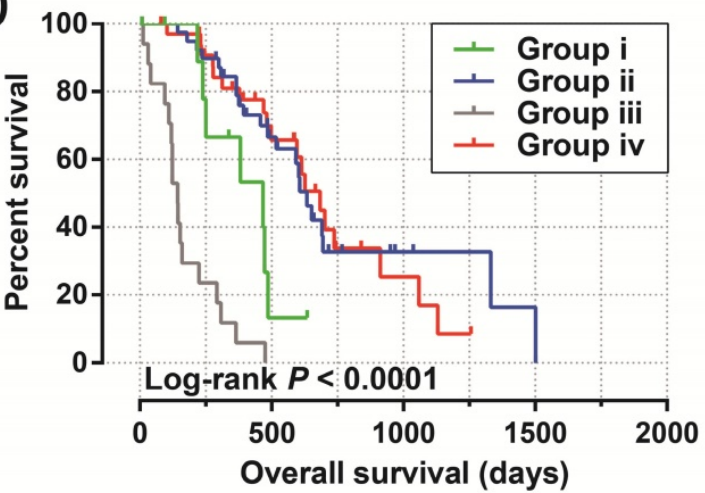

Figure 3. Joint effects survival analysis of LINPI and clinical parameters in PDAC OS. (A) Histological grade; (B) radiation therapy; (C) radical resection; (D) targeted molecular therapy. 


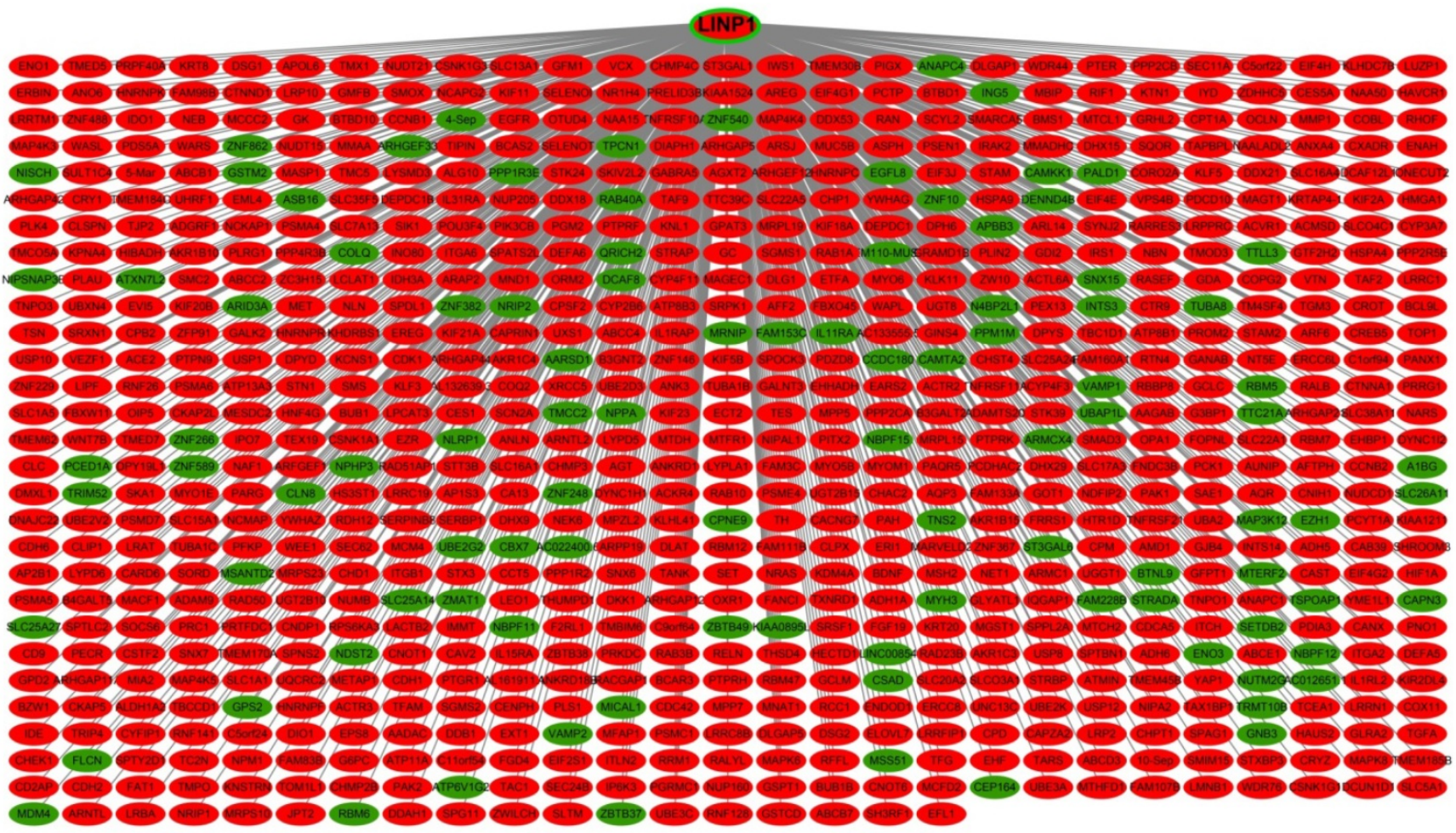

Positive co-expression genes

Negative co-expression genes

Co-expression relationship

Figure 4. Regulatory network of LINP1 co-expressed genes in PDAC tumor tissues.

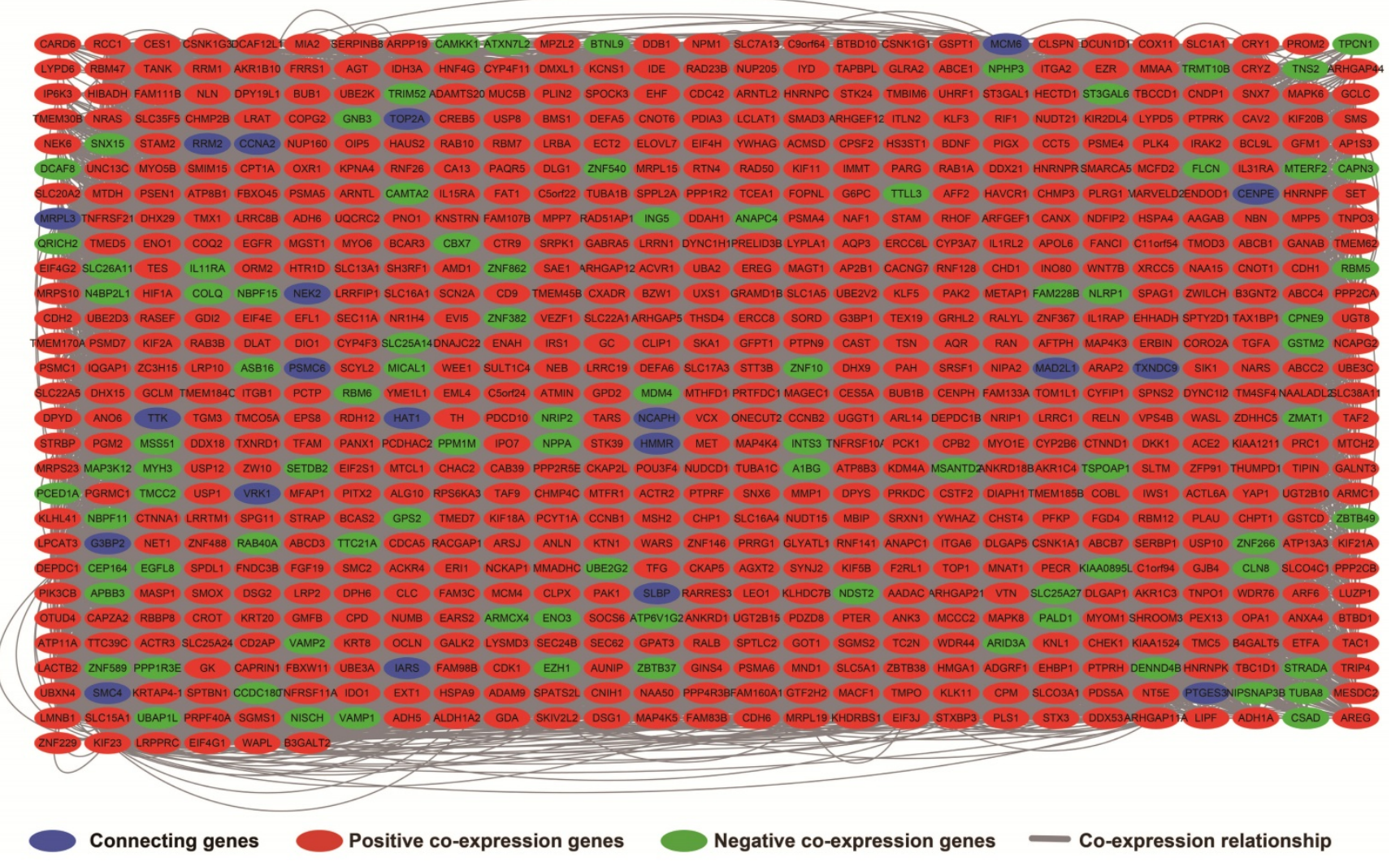

Figure 5. Gene-gene interaction regulatory network of LINPI co-expressed genes. 


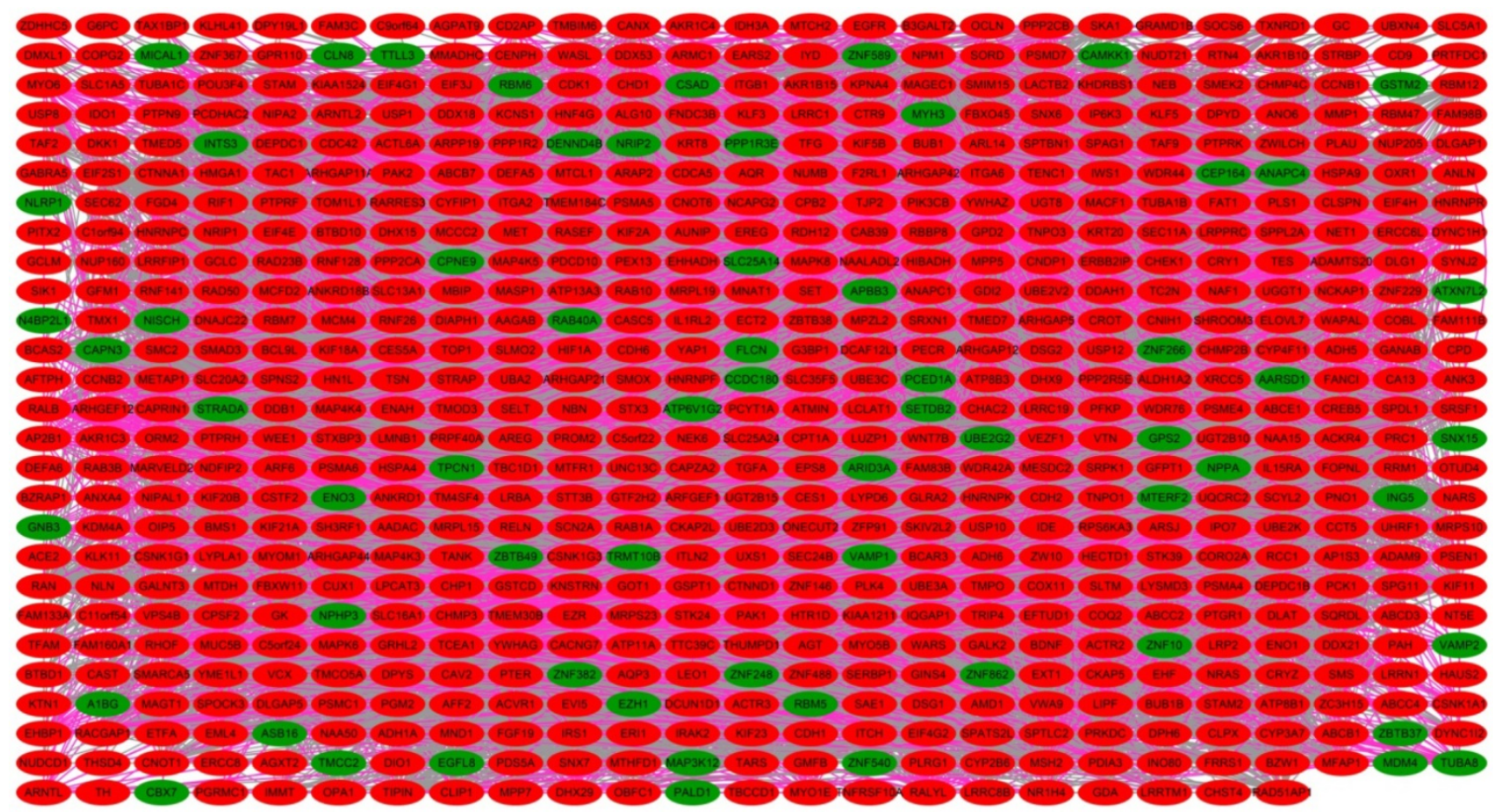

Positive co-expression genes

Negative co-expression genes

Co-expression relationship

Experimentally determined relationship

Figure 6. Protein-protein interaction regulatory network of LINPI co-expressed genes.

\section{DEGs screening and functional enrichment analysis}

The edgeR software package of the $\mathrm{R}$ platform was used to screen 700 DEGs between low- and high-LINP1 expression groups, of which 560 were down-regulated and 140 were up-regulated DEGs (Table S6). GO term enrichment analysis of DEGs between different LINP1 expression groups suggested that these DEGs are involved in cell junction, the B cell receptor signaling pathway, cell-cell signaling, cell differentiation, phosphatidylinositol-4,5-bisphosphate 3-kinase activity, positive regulation of $\mathrm{T}$ cell proliferation, growth factor activity, and positive regulation of protein kinase B signaling (Table S7). The results of BiNGO suggested that these DEGs participate in cell-cell signaling, regulation of $\mathrm{T}$ cell activation, cell differentiation, regulation of $\mathrm{T}$ cell proliferation, regulation of $\mathrm{B}$ cell proliferation, cell junction, regulation of cell proliferation and regulation of cell communication (Figure S2). The results of KEGG analysis suggested that these DEGs are involved in cytokine-cytokine receptor interaction, the PPAR signaling pathway, adipocytokine signaling pathway, and metabolism of xenobiotics by cytochrome P450 (Table S8). The GGI (Figure 7) and PPI (Figure 8) analyses suggested that these DEGs have complex interaction regulatory networks.

CMap analysis identified six small-molecule compounds that could be developed as potential LINP1 targeted drugs for the treatment of PDAC. The six small-molecule compounds were STOCK1N35874, fenofibrate, exisulind, NU-1025, vinburnine, and doxylamine (Figure 9). To compensate for the deficiency of functional enrichment of DEGs, we explored the potential mechanism underlying the role of LINP1 in PDAC using a GSEA approach. When c5 (c5.all.v6.2.symbols.gmt) was used as a reference gene set, we were unable to obtain statistically significant results. Use of c2 (c2.all.v6.2.symbols.gmt) as a reference gene set indicated that LINP1 may be involved in the following pathways in PDAC: metastasis and epithelial-mesenchymal transition (EMT), cell cycle, pancreatic cancer, apoptosis execution phase, cell-cell communication, cell junction, p53 dependent G1 DNA damage response, p53 independent G1/S DNA damage checkpoint, class I phosphoinositide 3-kinase (PI3KCI)/ Akt, pololike Kinase 1 (PLK1), tumor necrosis factor (TNF), mammalian/mechanistic target of rapamycin (mTOR), transforming growth factor-beta receptor (TGFBR), and the Wnt signaling pathway (Figure 10, Table S9). 


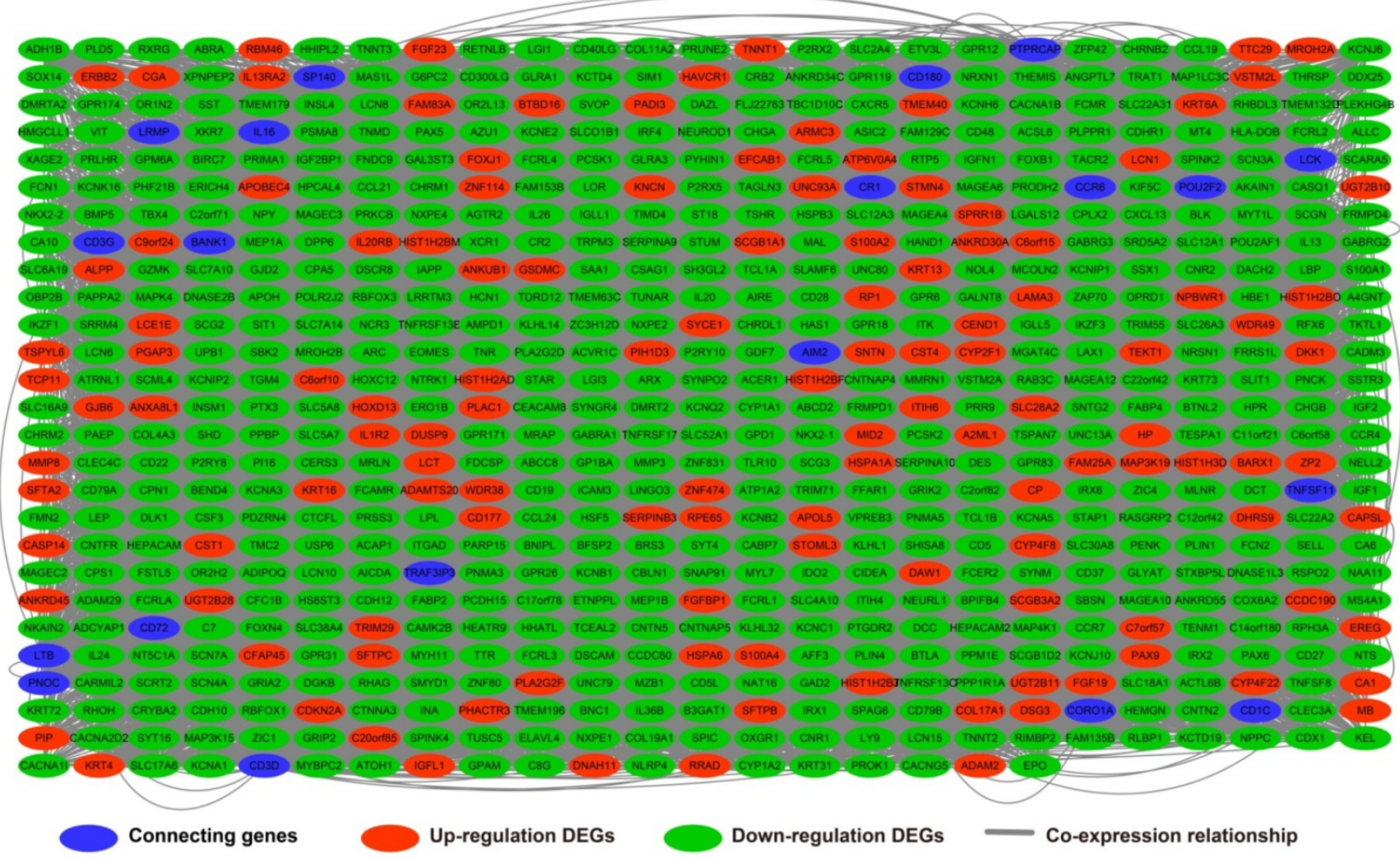

Figure 7. Gene-gene interaction regulatory network of differentially expressed genes (DEGs) between high- and low-LINPI expression groups.

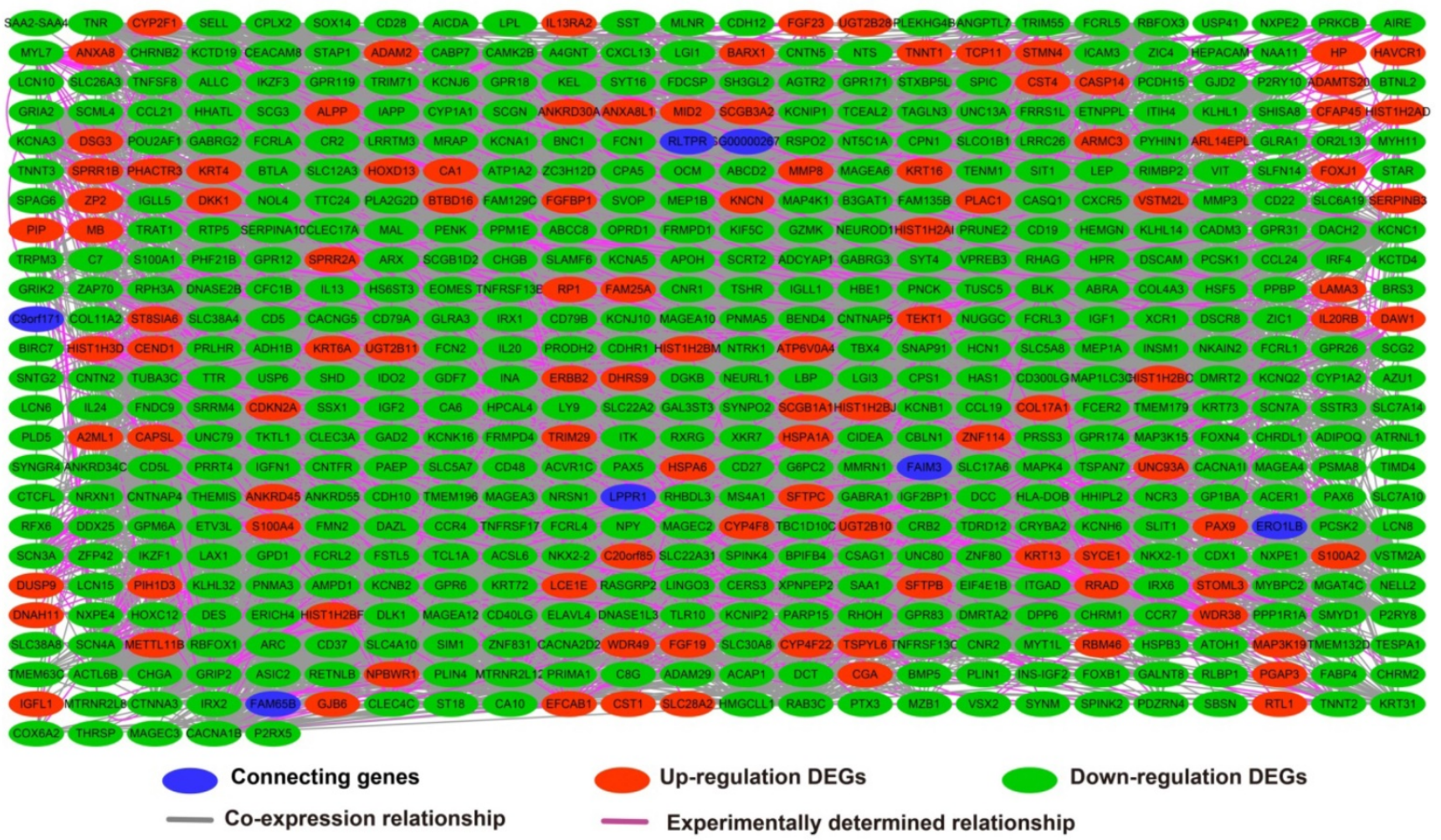

Figure 8. Protein-protein interaction regulatory network of DEGs between high- and low-LINPI expression groups. 

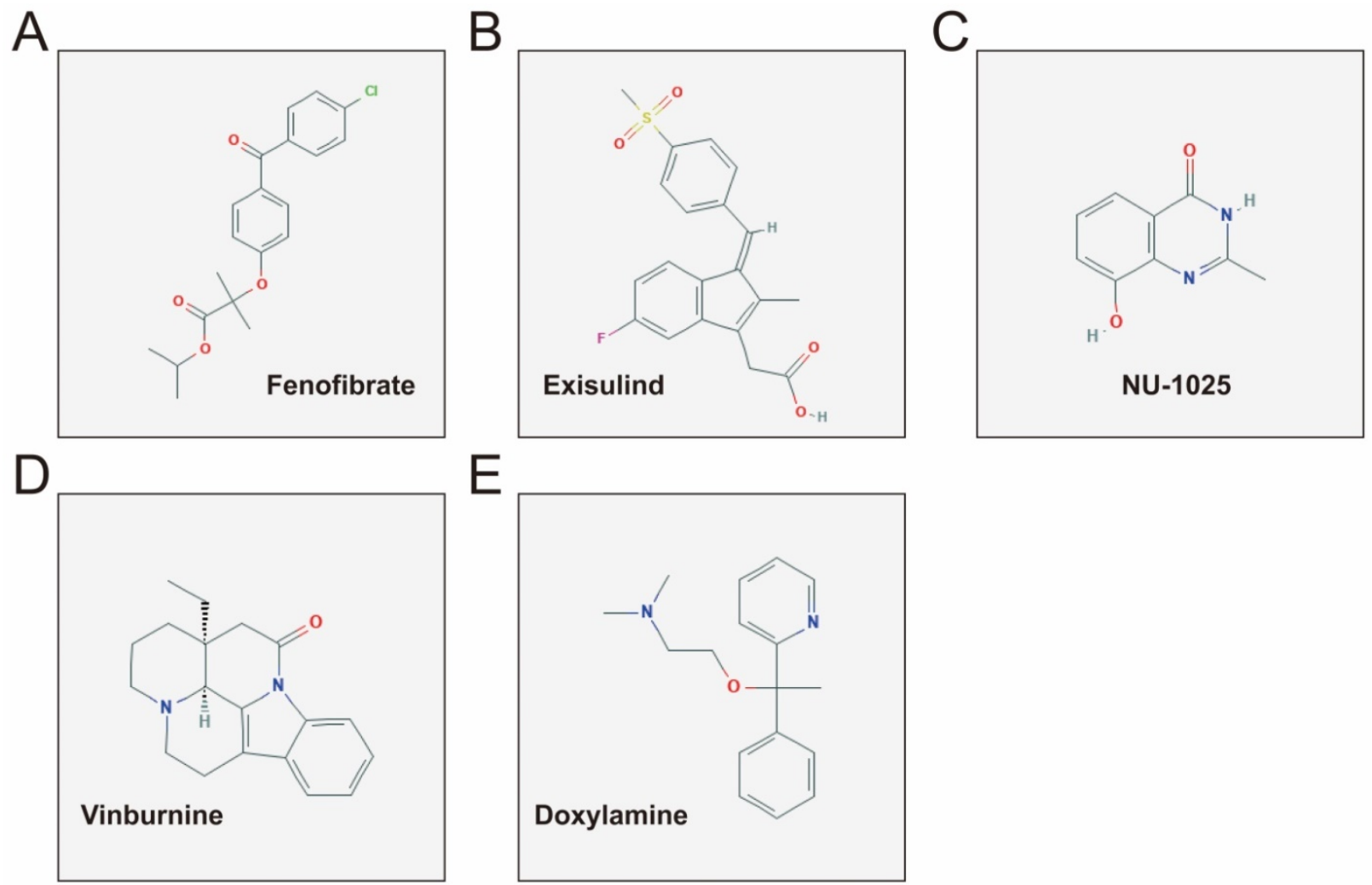

E

\begin{tabular}{lcccccc}
\hline CMap name & Mean connective score & $\mathbf{n}$ & Enrichment & P value & Specificity & Percent non-null \\
\hline STOCK1N-35874 & -0.74 & 2 & -0.974 & 0.00139 & 0.0066 & 100 \\
Fenofibrate & -0.476 & 3 & -0.858 & 0.00563 & 0.0323 & 66 \\
Exisulind & -0.489 & 2 & -0.939 & 0.00767 & 0.0058 & 100 \\
NU-1025 & -0.41 & 2 & -0.938 & 0.00799 & 0.0107 & 100 \\
Vinburnine & -0.359 & 4 & -0.635 & 0.04279 & 0.0851 & 50 \\
Doxylamine & -0.278 & 5 & -0.561 & 0.04994 & 0.1925 & 60 \\
\hline
\end{tabular}

Figure 9. CMap analysis results and small molecule compound structure. Chemical structure of Fenofibrate (A), Exisulind (B), NU-1025 (C), Vinburnine (D), Doxylamine (E), and CMap analysis results $(\mathbf{F})$. Notes: The structure of STOCK IN-35874 is not available on the PubChem database.

\section{Discussion}

Liang et al. suggested that LINP1 acts as an oncogene in breast cancer. Breast cancer patients with high LINP1expression have shorter disease-free survival (DFS) and OS than those with low expression [9]. Inhibition of LINP1 expression in breast cancer cell lines promotes apoptosis and induces cell cycle arrest. LINP1 is involved in distant metastasis in breast cancer by regulating EMT and the p53 pathway. LINP1 is expressed at higher levels in breast cancer patients with distant metastasis than in those without distant metastasis [9]. The results of Liang et al. were confirmed by a study published by Liu et al., which indicated that breast cancer patients with high LINP1expression have a poor prognosis, and LINP1 is significantly overexpressed in breast cancer tissues [7]. Zhang et al. used a clinically guided genetic screening approach in triple-negative breast cancer
(TNBC) and found that LINP1 is not only highly expressed in TNBC tumor tissues, but also participates in the regulation of the non-homologous end joining (NHEJ) pathway through $\mathrm{Ku} 80$ and DNA-PKcs [28]. LINP1 is also involved in the regulation of the p53 and EGFR signaling pathways, thereby affecting the sensitivity of breast cancer cell lines to radiotherapy [28]. Similar studies were performed in cervical cancer. Wang et al. reported that LINP1 is involved in the NHEJ pathway by regulating Ku80 and DNA-PKcs in cervical cancer, and it modulates the radiation sensitivity of cervical cancer cells [29]. LINP1 expression levels are notably increased in cervical cancer tumor tissues [29]. Wu et al. observed that LINP1 acts as an oncogene in prostate cancer [8]. The expression level of LINP1 is notably up-regulation in prostate cancer tumor tissues than in adjacent tumor tissues, and the OS time of high LINP1expression patients is notably shorter than 
these with low LINP1 expression [8]. LINP1 expression is also related to $\mathrm{T}$ stage, lymph node metastasis, and distant metastasis in prostate cancer. Analysis of the underlying molecular mechanism showed that LINP1 regulates the malignant phenotype of prostate cancer cells through the p53 signaling pathway [8]. De Silva et al. suggested that inhibiting the expression of LINP1 in TNBC cell lines blocks the interaction between insulin like growth factor binding protein 3 and non-POU domain containing octamer binding-splicing factor proline and glutamine rich, thereby affecting the DNA damage repair of cells. These results suggest that LINP1 affects the chemotherapy sensitivity of TNBC, and may be a therapeutic target for the treatment of TNBC [30]. However, studies on the role of LINP1 in cancer have reported inconsistent results. Zhang et al. reported that LINP1 acts as a tumor suppressor gene in lung cancer, and silencing of LINP1 in lung cancer cell lines affects the migration, invasion, and stemness phenotypes of lung cancer cell lines by inhibiting EMT [31].
A

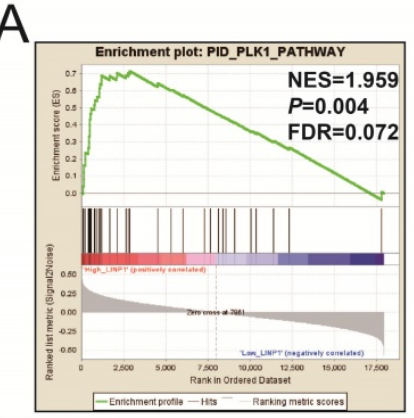

E

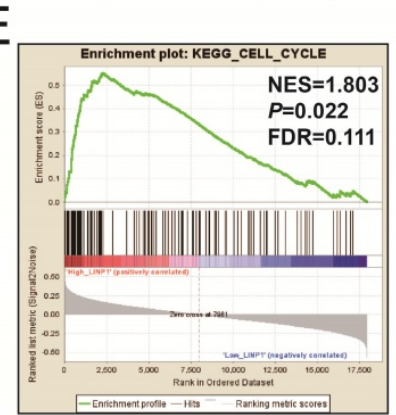

I

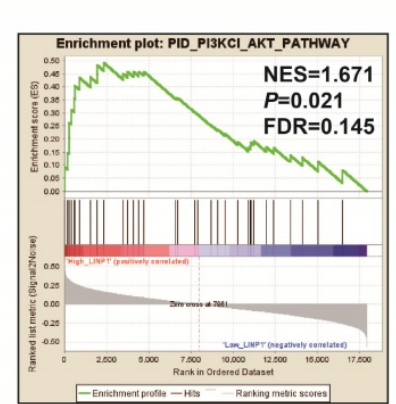

M

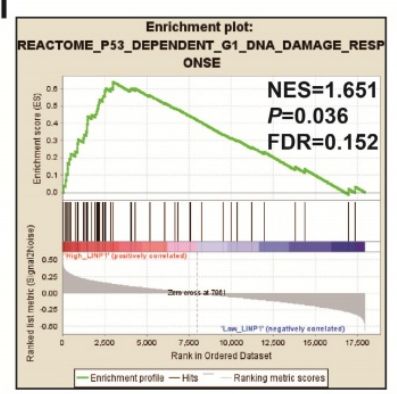

B

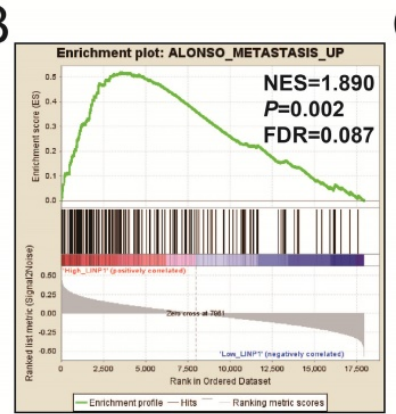

$\mathrm{F}$

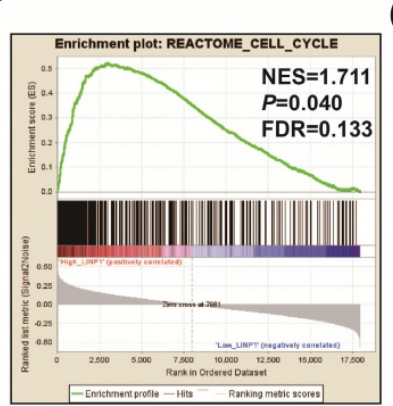

$\mathrm{J}$

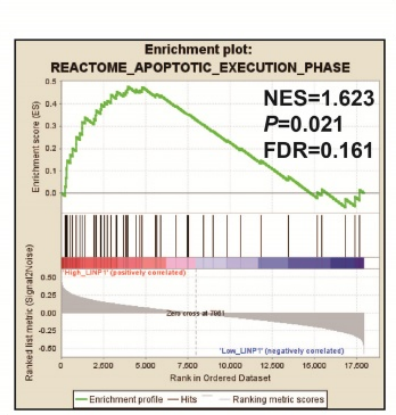

$\mathrm{N}$

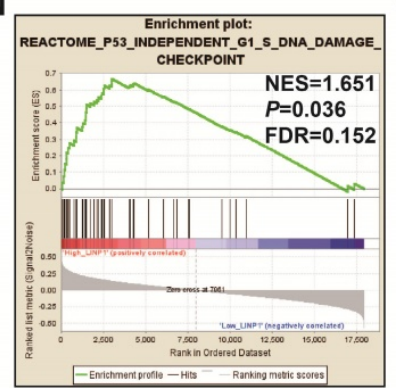

C

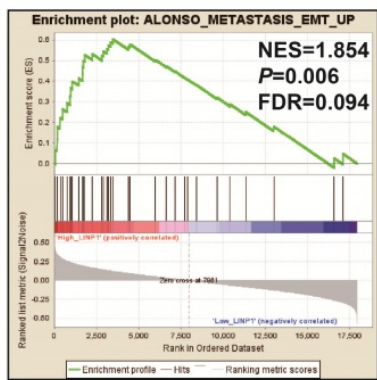

G

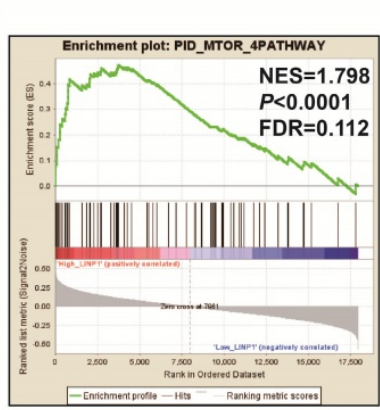

K

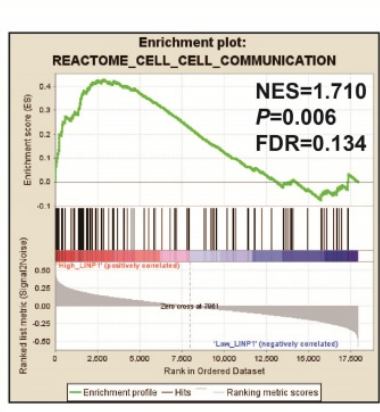

O

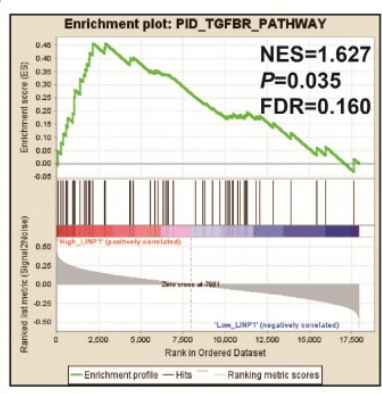

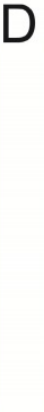

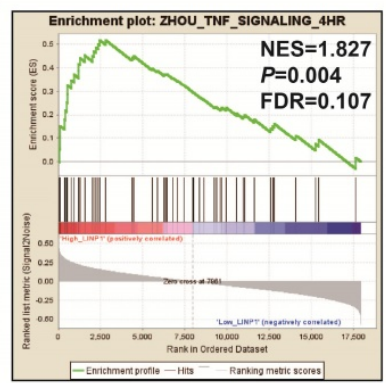

$\mathrm{H}$
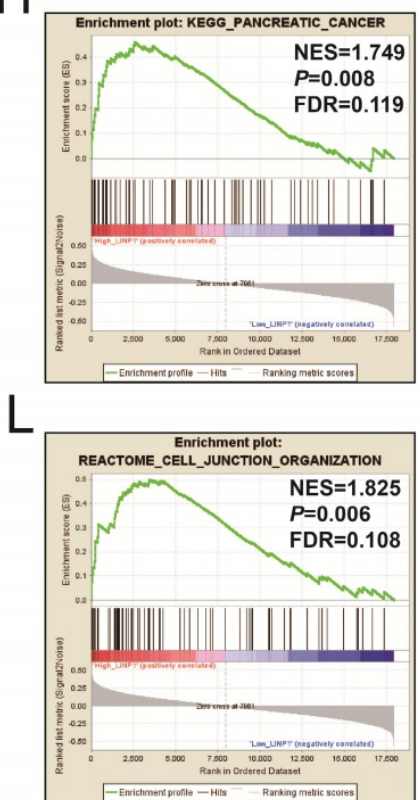

$P$

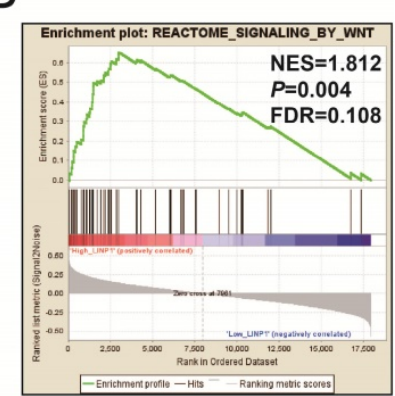

Figure 10. GSEA results of the high LINPI expression group in early stage PDAC using the c5 reference gene set (A-P). (A), PID PLK1 PATHWAY; (B), ALONSO METASTASIS UP; (C), ALONSO METASTASIS EMT UP; (E),KEGG CELL CYCLE; (F),REACTOME CELL CYCLE; (G), PID MTOM 4 PATHWAY; (H), KEGG PANCREATIC CANCER; (I), PID PI3KCI AKT PATHWAY; (J), REACTOME APOPTOTIC EXECUTION PHASE; (K), REACROME CELL CELL COMMUNICATION; (L), REACROME CELL JUNCTION ORGANIZTION; (M), REACROME P53 DEPENDENT GI DNA DAMAGE RESPONE; (N), REACROME P53 INDEPENDENT GI S DNA DAMAGE CHECKPOINT; (O), PID TGFBR PATHWAY; (P), REACTOME SIGNALING BY WNT. 
Regarding the six potential LINP1 targeted drugs for the treatment of PDAC, a literature review did not identify previous studies on the interaction between these drugs and LINP1. Most of these drugs, except doxylamine and vinburnine, were reported to have antitumor effects. In previous studies, CMAP analysis based on genome-wide expression profiling datasets identified STOCK1N-35874 as a potential targeted therapy for colon adenocarcinoma and prostate carcinoma $[32,33]$. NU1025 is involved in regulating the sensitivity of human cervical cancer HeLa cells to the triazoloacridone compound c-1305 through the p53 pathway, thereby synergistically participating in tumor inhibition [34]. Fenofibrate has anticancer effects in a variety of cancers [35], and it increases the sensitivity of tumors to chemotherapy and radiotherapy [36, 37]. A literature review revealed that fenofibrate has anticancer effects in many malignancies, including pancreatic cancer [38], lung adenocarcinoma [39], hepatocellular carcinoma [40], melanoma [41], glioblastoma [42, 43], oral cancer $[44,45]$, prostate cancer [46, 47], breast cancer [48], neuroblastoma [49], and angiosarcomas [50]. Fenofibrate also increases the sensitivity of esophageal carcinoma [51, 52] and head and neck squamous cell carcinoma [37] to radiotherapy, and that of breast cancer to chemotherapy [36]. Exisulind is widely reported to have anticancer effects in a variety of malignancies, including non-small cell lung cancer [53], colon cancer [54-58], prostate cancer [59], breast cancer [60], head and neck squamous cell carcinoma [61], and pan-cancer [62]. Low-dose celecoxib combined with exisulind can affect the tumorigenesis of prostate cancer by regulating pathways such as EGFR, Akt, androgen receptor, and cyclin D1. Exisulind was suggested as a potential drug for the prevention of prostate cancer [63].

Analysis of the potential functional mechanisms of LINP1 in PDAC showed that LINP1 is involved in the regulation of several cellular processes and pathways related to cell proliferation, cell cycle, and cell adhesion. Cell adhesion related biological processes and pathways are related to tumor metastasis and the malignant phenotype.

The present study has several limitations. First, because of the short survival time of the patients included in this study, the nomogram and time dependent ROC curve analysis were limited to 4 years. Second, because the study included a single cohort, the results need to be verified with multicenter studies and larger sample sizes. Third, the proposed underlying mechanisms need to be confirmed by performing in vivo and in vitro experiments. Nevertheless, the present study is the first to report the clinical application value and potential molecular mechanism of LINP1 in PDAC patients, as well as the screening of targeted drugs. The present study not only found the LINP1 can be used as a prognostic biomarker for PDAC, but also investigated the mechanism of LINP1 in PDAC by using TCGA genome-wide RNA-sequencing dataset. At the same time, CMAP was used to screen out the targeted drugs of LINP1 in PDAC. Once these findings are validated in multi-center dataset, and small molecule drugs are demonstrated in in vivo and in vitro experiments, our findings will provide important application values for prognosis prediction, postoperative surveillance management and treatment of PDAC.

\section{Conclusions}

LINP1 may serve as a prognostic biomarker in early stage PDAC. Analysis of genome-wide co-expressed genes, DEGs screening, and GSEA approaches suggested that LINP1 is involved in the regulation of cell cycle, cell proliferation, and cell adhesion-related biological processes in PDAC. In addition, six small-molecule compounds including STOCK1N-35874, fenofibrate, exisulind, NU-1025, vinburnine, and doxylamine were identified as potential LINP1-targeted drugs for the treatment of PDAC. However, the present results need to be verified in future studies with larger sample sizes.

\section{Supplementary Material}

Supplementary figures and tables. http://www.jcancer.org/v11p5556s1.zip

\section{Acknowledgements}

This work was supported in part by the National Natural Science Foundation of China (No.: 81560535, 81802874, 81072321, and 30460143), Natural Science Foundation of Guangxi Province of China (Grant No. 2018GXNSFBA138013 and 2018GXNSFAA050119), 2009 Program for New Century Excellent Talents in University (NCET), Guangxi Natural Sciences Foundation (No. GuiKeGong 1104003A-7), and Guangxi Health Ministry Medicine Grant (Key-Scientific Research-Grant Z201018). The present study is also partly supported by Scientific Research Fund of the Health and Family Planning Commission of Guangxi Zhuang Autonomous Region (Z2016318, Z2012072), Key laboratory of High-Incidence-Tumor Prevention \& Treatment (Guangxi Medical University), Ministry of Education (GKE2018-01, GKE2019-11), the Guangxi Key R \& D Program (GKEAB18221019), The Basic Ability Improvement Project for Middle-aged and Young Teachers in Colleges and Universities in Guangxi (2018KY0110), 2018 Innovation Project of Guangxi Graduate 
Education (JGY2018037), Guangxi Key Laboratory for the Prevention and Control of Viral Hepatitis (No.GXCDCKL201902), Guangxi emergency and medical rescue talents highland $\bullet$ Key Laboratory of Emergency Medicine in Guangxi University-Open Project (GXJZ201615), Department of education of Guangxi Zhuang Autonomous Region teaching reform project (2015JGA179) and innovation project (JGY2015039). As well as, the present study is also partly supported by Research Institute of Innovative Think-tank in Guangxi Medical University (The geneenvironment interaction in hepatocarcinogenesis in Guangxi HCCs and its translational applications in the HCC prevention). We would also acknowledge the supported by the National Key Clinical Specialty Programs (General Surgery \& Oncology) and the Key Laboratory of Early Prevention \& Treatment for Regional High-Incidence-Tumor (Guangxi Medical University), Ministry of Education, China. The authors thank the contributors of The Cancer Genome Atlas (https://cancergenome.nih.gov/) and UCSC Xena (http://xena.ucsc.edu/) for sharing the PDAC data on open access.

\section{Competing Interests}

The authors have declared that no competing interest exists.

\section{References}

1. Kamisawa T, Wood LD, Itoi T, Takaori K. Pancreatic cancer. Lancet. 2016; 388: 73-85.

2. Ryan DP, Hong TS, Bardeesy N. Pancreatic adenocarcinoma. The New England journal of medicine. 2014; 371: 1039-49.

3. Siegel R, Ma J, Zou Z, Jemal A. Cancer statistics, 2014. CA: a cancer journal for clinicians. 2014; 64: 9-29.

4. Previdi MC, Carotenuto P, Zito D, Pandolfo R, Braconi C. Noncoding RNAs as novel biomarkers in pancreatic cancer: what do we know? Future oncology. 2017; 13: 443-53.

5. Cancer Genome Atlas Research Network. Electronic address aadhe, Cancer Genome Atlas Research N. Integrated Genomic Characterization of Pancreatic Ductal Adenocarcinoma. Cancer cell. 2017; 32(e13): 185-203.

6. Cancer Genome Atlas Research N, Weinstein JN, Collisson EA, Mills GB, Shaw KR, Ozenberger BA, et al. The Cancer Genome Atlas Pan-Cancer analysis project. Nature genetics. 2013; 45: 1113-20.

7. Liu XM, Yang B, Han J. Increased long noncoding RNA LINP1 expression and its prognostic significance in human breast cancer. European review for medical and pharmacological sciences. 2018; 22: 8749-54.

8. Wu HF, Ren LG, Xiao JQ, Zhang Y, Mao XW, Zhou LF. Long non-coding RNA LINP1 promotes the malignant progression of prostate cancer by regulating p53. European review for medical and pharmacological sciences. 2018; 22: 4467-76.

9. Liang Y, Li Y, Song X, Zhang N, Sang Y, Zhang H, et al. Long noncoding RNA LINP1 acts as an oncogene and promotes chemoresistance in breast cancer. Cancer biology \& therapy. 2018; 19: 120-31

10. Liao X, Han C, Wang X, Huang K, Yu T, Yang C, et al. Prognostic value of minichromosome maintenance mRNA expression in early-stage pancreatic ductal adenocarcinoma patients after pancreaticoduodenectomy. Cancer management and research. 2018; 10: 3255-71.

11. Liao X, Huang K, Huang R, Liu X, Han C, Yu L, et al. Genome-scale analysis to identify prognostic markers in patients with early-stage pancreatic ductal adenocarcinoma after pancreaticoduodenectomy. OncoTargets and therapy. 2017; 10: 4493-506.

12. Liao X, Wang X, Huang K, Yang C, Yu T, Han C, et al. Genome-scale analysis to identify prognostic microRNA biomarkers in patients with early stage pancreatic ductal adenocarcinoma after pancreaticoduodenectomy. Cancer management and research. 2018; 10: 2537-51.

13. Huang da W, Sherman BT, Lempicki RA. Systematic and integrative analysis of large gene lists using DAVID bioinformatics resources. Nature protocols. 2009; 4: 44-57.
14. Jiao X, Sherman BT, Huang da W, Stephens R, Baseler MW, Lane HC, et al. DAVID-WS: a stateful web service to facilitate gene/protein list analysis. Bioinformatics. 2012; 28: 1805-6.

15. Maere S, Heymans K, Kuiper M. BiNGO: a Cytoscape plugin to assess overrepresentation of gene ontology categories in biological networks. Bioinformatics. 2005; 21: 3448-9.

16. Warde-Farley D, Donaldson SL, Comes O, Zuberi K, Badrawi R, Chao P, et al. The GeneMANIA prediction server: biological network integration for gene prioritization and predicting gene function. Nucleic acids research. 2010; 38: W214-20.

17. Mostafavi S, Ray D, Warde-Farley D, Grouios C, Morris Q. GeneMANIA: a real-time multiple association network integration algorithm for predicting gene function. Genome biology. 2008; 9 Suppl 1: S4.

18. Szklarczyk D, Franceschini A, Wyder S, Forslund K, Heller D, Huerta-Cepas I, et al. STRING v10: protein-protein interaction networks, integrated over the tree of life. Nucleic acids research. 2015; 43: D447-52.

19. von Mering C, Jensen LJ, Snel B, Hooper SD, Krupp M, Foglierini M, et al. STRING: known and predicted protein-protein associations, integrated and transferred across organisms. Nucleic acids research. 2005; 33: D433-7.

20. von Mering C, Huynen M, Jaeggi D, Schmidt S, Bork P, Snel B. STRING: a database of predicted functional associations between proteins. Nucleic acids research. 2003; 31: 258-61.

21. Robinson MD, McCarthy DJ, Smyth GK. edgeR: a Bioconductor package for differential expression analysis of digital gene expression data. Bioinformatics. 2010; 26: 139-40.

22. Lamb J, Crawford ED, Peck D, Modell JW, Blat IC, Wrobel MJ, et al. The Connectivity Map: using gene-expression signatures to connect small molecules, genes, and disease. Science. 2006; 313: 1929-35.

23. Lamb J. The Connectivity Map: a new tool for biomedical research. Nature reviews Cancer. 2007; 7: 54-60.

24. Kim S, Chen J, Cheng T, Gindulyte A, He J, He S, et al. PubChem 2019 update: improved access to chemical data. Nucleic acids research. 2019; 47: D1102-D9.

25. Subramanian A, Tamayo P, Mootha VK, Mukherjee S, Ebert BL, Gillette MA, et al. Gene set enrichment analysis: a knowledge-based approach for interpreting genome-wide expression profiles. Proceedings of the National Academy of Sciences of the United States of America. 2005; 102: 15545-50.

26. Liberzon A, Subramanian A, Pinchback R, Thorvaldsdottir H, Tamayo P, Mesirov JP. Molecular signatures database (MSigDB) 3.0. Bioinformatics. 2011; 27: 1739-40.

27. Liberzon A, Birger C, Thorvaldsdottir H, Ghandi M, Mesirov JP, Tamayo P. The Molecular Signatures Database (MSigDB) hallmark gene set collection. Cell systems. 2015; 1: 417-25.

28. Zhang Y, He Q, Hu Z, Feng Y, Fan L, Tang Z, et al. Long noncoding RNA LINP1 regulates repair of DNA double-strand breaks in triple-negative breast cancer. Nature structural \& molecular biology. 2016; 23: 522-30.

29. Wang X, Liu H, Shi L, Yu X, Gu Y, Sun X. LINP1 facilitates DNA damage repair through non-homologous end joining (NHEJ) pathway and subsequently decreases the sensitivity of cervical cancer cells to ionizing radiation. Cell cycle. 2018; 17: 439-47.

30. de Silva HC, Lin MZ, Phillips L, Martin JL, Baxter RC. IGFBP-3 interacts with NONO and SFPQ in PARP-dependent DNA damage repair in triple-negative breast cancer. Cellular and molecular life sciences : CMLS. 2019; 76: 2015-30.

31. Zhang C, Hao Y, Wang Y, Xu J, Teng Y, Yang X. TGF-beta/SMAD4-Regulated LncRNA-LINP1 Inhibits Epithelial-Mesenchymal Transition in Lung Cancer. International journal of biological sciences. 2018; 14: 1715-23.

32. Xi WD, Liu YJ, Sun XB, Shan J, Yi L, Zhang TT. Bioinformatics analysis of RNA-seq data revealed critical genes in colon adenocarcinoma. European review for medical and pharmacological sciences. 2017; 21: 3012-20.

33. $\mathrm{Xu} \mathrm{A}, \mathrm{Sun} \mathrm{S}$. Genomic profiling screens small molecules of metastatic prostate carcinoma. Oncology letters. 2015; 10: 1402-8

34. Sabisz M, Wesierska-Gadek J, Skladanowski A. Increased cytotoxicity of an unusual DNA topoisomerase II inhibitor compound C-1305 toward HeLa cells with downregulated PARP-1 activity results from re-activation of the p53 pathway and modulation of mitotic checkpoints. Biochemical pharmacology. 2010; 79: 1387-97.

35. Lian X, Wang G, Zhou H, Zheng Z, Fu Y, Cai L. Anticancer Properties of Fenofibrate: A Repurposing Use. Journal of Cancer. 2018; 9: 1527-37.

36. Sun J, Zheng Z, Chen Q, Pan Y, Quan M, Dai Y. Fenofibrate potentiates chemosensitivity to human breast cancer cells by modulating apoptosis via AKT/NF-kappaB pathway. OncoTargets and therapy. 2019; 12: 773-83.

37. Liu J, Ge YY, Zhu HC, Yang X, Cai J, Zhang C, et al. Fenofibrate increases radiosensitivity in head and neck squamous cell carcinoma via inducing G2/M arrest and apoptosis. Asian Pacific journal of cancer prevention APJCP. 2014; 15: 6649-55.

38. Hu D, Su C, Jiang M, Shen Y, Shi A, Zhao F, et al. Fenofibrate inhibited pancreatic cancer cells proliferation via activation of p53 mediated by upregulation of LncRNA MEG3. Biochemical and biophysical research communications. 2016; 471: 290-5.

39. Piwowarczyk K, Kwiecien E, Sosniak J, Zimolag E, Guzik E Sroka J, et al. Fenofibrate Interferes with the Diapedesis of Lung Adenocarcinoma Cells through the Interference with Cx43/EGF-Dependent Intercellular Signaling. Cancers. 2018; 10.

40. You BJ, Hour MJ, Chen LY, Luo SC, Hsu PH, Lee HZ. Fenofibrate induces human hepatoma Hep3B cells apoptosis and necroptosis through inhibition of thioesterase domain of fatty acid synthase. Scientific reports. 2019; 9: 3306. 
41. Dana N, Haghjooy Javanmard S, Vaseghi G. The effect of fenofibrate, a PPARalpha activator on toll-like receptor-4 signal transduction in melanoma both in vitro and in vivo. Clinical \& translational oncology : official publication of the Federation of Spanish Oncology Societies and of the National Cancer Institute of Mexico. 2019

42. Han D, Wei W, Chen X, Zhang Y, Wang Y, Zhang J, et al. NF-kappaB/RelA-PKM2 mediates inhibition of glycolysis by fenofibrate in glioblastoma cells. Oncotarget. 2015; 6: 26119-28.

43. Han DF, Zhang JX, Wei WJ, Tao T, Hu Q, Wang YY, et al. Fenofibrate induces G0/G1 phase arrest by modulating the PPARalpha/FoxO1/p27 kip pathway in human glioblastoma cells. Tumour biology : the journal of the International Society for Oncodevelopmental Biology and Medicine. 2015; 36: 3823-9.

44. Jan CI, Tsai MH, Chiu CF, Huang YP, Liu CJ, Chang NW. Fenofibrate Suppresses Oral Tumorigenesis via Reprogramming Metabolic Processes: Potential Drug Repurposing for Oral Cancer. International journal of biological sciences. 2016; 12: 786-98.

45. Tsai SC, Tsai MH, Chiu CF, Lu CC, Kuo SC, Chang NW, et al. AMPK-dependent signaling modulates the suppression of invasion and migration by fenofibrate in CAL 27 oral cancer cells through NF-kappaB pathway. Environmental toxicology. 2016; 31: 866-76.

46. Lian X, Gu J, Gao B, Li Y, Damodaran C, Wei W, et al. Fenofibrate inhibits mTOR-p70S6K signaling and simultaneously induces cell death in human prostate cancer cells. Biochemical and biophysical research communications. 2018; 496: 70-5.

47. Tao T, Zhao F, Xuan Q, Shen Z, Xiao J, Shen Q. Fenofibrate inhibits the growth of prostate cancer through regulating autophagy and endoplasmic reticulum stress. Biochemical and biophysical research communications. 2018; 503: 2685-9.

48. Nguyen $\mathrm{CH}$, Huttary N, Atanasov AG, Chatuphonprasert W, Brenner S, Fristiohady A, et al. Fenofibrate inhibits tumour intravasation by several independent mechanisms in a 3-dimensional co-culture model. International journal of oncology. 2017; 50: 1879-88.

49. Su C, Shi A, Cao G, Tao T, Chen R, Hu Z, et al. Fenofibrate suppressed proliferation and migration of human neuroblastoma cells via oxidative stress dependent of TXNIP upregulation. Biochemical and biophysical research communications. 2015; 460: 983-8.

50. Majeed Y, Upadhyay R, Alhousseiny S, Taha T, Musthak A, Shaheen Y, et al. Potent and PPARalpha-independent anti-proliferative action of the hypolipidemic drug fenofibrate in VEGF-dependent angiosarcomas in vitro. Scientific reports. 2019; 9: 6316 .

51. Ge Y, Liu J, Yang X, Zhu H, Yang B, Zhao K, et al. Fenofibrate enhances radiosensitivity of esophageal squamous cell carcinoma by suppressing hypoxia-inducible factor-1alpha expression. Tumour biology : the journal of the International Society for Oncodevelopmental Biology and Medicine. 2014; 35: 10765-71.

52. Li XQ, Zhou JD, Zou ST, Yu J, Meng XJ, Wu JC. Enhancement of radiosensitivity in human esophageal carcinoma cells by fenofibrate and its potential mechanism. Tumori. 2015; 101: 123-30.

53. Attia S, Traynor AM, Kim K, Merchant JJ, Hoang T, Ahuja HG, et al. Phase I/II study of vinorelbine and exisulind as first-line treatment of advanced non-small cell lung cancer in patients at least 70 years old: a wisconsin oncology network study. Journal of thoracic oncology : official publication of the International Association for the Study of Lung Cancer. 2008; 3: 1018-25.

54. Aono Y, Horinaka M, Iizumi Y, Watanabe M, Taniguchi T, Yasuda S, et al. Sulindac sulfone inhibits the mTORC1 pathway in colon cancer cells by directly targeting voltage-dependent anion channel 1 and 2. Biochemical and biophysical research communications. 2018; 505: 1203-10.

55. Pitari GM, Li T, Baksh RI, Waldman SA. Exisulind and guanylyl cyclase C induce distinct antineoplastic signaling mechanisms in human colon cancer cells. Molecular cancer therapeutics. 2006; 5: 1190-6.

56. Lim SJ, Lee YJ, Lee E. p38MAPK inhibitor SB203580 sensitizes human SNU-C4 colon cancer cells to exisulind-induced apoptosis. Oncology reports. 2006; 16: 1131-5.

57. Giladi N, Kazanov D, Shpitz B, Aroch I, Kraus S, Arber N. Curcumin potentiates the pro-apoptotic effects of sulindac sulfone in colorectal cancer. Expert opinion on investigational drugs. 2010; 19 Suppl 1: S117-24.

58. Lim SJ, Lee YJ, Park DH, Lee E, Choi MK, Park W, et al. Alpha-tocopheryl succinate sensitizes human colon cancer cells to exisulind-induced apoptosis. Apoptosis : an international journal on programmed cell death. 2007; 12: 423-31.

59. Webster WS, Leibovich BC. Exisulind in the treatment of prostate cancer. Expert review of anticancer therapy. 2005; 5: 957-62.

60. Lim JT, Joe AK, Suzui M, Shimizu M, Masuda M, Weinstein IB. Sulindac sulfide and exisulind inhibit expression of the estrogen and progesterone receptors in human breast cancer cells. Clinical cancer research : an official journal of the American Association for Cancer Research. 2006; 12: 3478-84.

61. Sauter A, Soulsby H, Hormann K, Naim R. Sulindac sulfone induces a decrease of beta-catenin in HNSCC. Anticancer research. 2010; 30: 339-43.

62. Garcia AA, Iqbal S, Quinn D, Edwards S, Lenz HJ, Weber J. Phase I clinical trial of weekly docetaxel and exisulind, a novel inducer of apoptosis. Investigational new drugs. 2006; 24: 79-83.

63. Narayanan BA, Reddy BS, Bosland MC, Nargi D, Horton L, Randolph C, et al Exisulind in combination with celecoxib modulates epidermal growth factor receptor, cyclooxygenase-2, and cyclin D1 against prostate carcinogenesis: in vivo evidence. Clinical cancer research : an official journal of the American Association for Cancer Research. 2007; 13: 5965-73. 